Article

\title{
Non-Enzymatic Electrochemical Sensor Based on Sliver Nanoparticle-Decorated Carbon Nanotubes
}

\author{
Dongqing $\mathrm{Xu}^{1}{ }^{1}$, Bingbing Hou ${ }^{1}$, Lisheng Qian ${ }^{1, *}$, Xueji Zhang ${ }^{1,2, *}$ and Guodong Liu ${ }^{1, *}$ \\ 1 Institute of Biomedical and Health Science, School of Life and Health Science, Anhui Science and Technology \\ University, Fengyang 233100, Anhui, China; xudq@ahstu.edu.cn (D.X.); Houbb@ahstu.edu.cn (B.H.) \\ 2 School of Biomedical Engineering, Shenzhen University Healthy Science Center, \\ Shenzhen 518060, Guangdong, China \\ * Correspondence: qianls@ahstu.edu.cn (L.Q.); zhangxueji@szu.edu.cn (X.Z.); liugd@ahstu.edu.cn (G.L.); \\ Tel.: +86-5506732096 (L.Q. \& X.Z. \& G.L.); Fax: +86-5506733165 (L.Q. \& X.Z. \& G.L.)
}

Academic Editor: Ondrej Zitka

Received: 28 August 2019; Accepted: 17 September 2019; Published: 19 September 2019

\begin{abstract}
The authors report a non-enzymatic electrochemical sensor based on a sliver nanoparticle-decorated carbon nanotube (AgNPs-MWCNT). Highly-dispersed AgNPs were loaded on the MWCNT surface though a simple and facile two-step method. The morphology, components, and the size of the AgNPs-MWCNT nanocomposite were characterized by transmission electron microscopy, X-ray diffraction, and ICP analysis. Benefitting from the synergistic effect between the AgNPs and MWCNT, the AgNPs-MWCNT nanocomposite exhibited high electrocatalytic activity for $\mathrm{H}_{2} \mathrm{O}_{2}$; the AgNPs-MWCNT electrochemical sensor was prepared by coating the AgNPs-MWCNT nanocomposite on a glassy carbon electrode, and it showed a fast and sensitive response to $\mathrm{H}_{2} \mathrm{O}_{2}$ with a linear range of 1 to $1000 \mu \mathrm{M}$. The detection limit was $0.38 \mu \mathrm{M}(\mathrm{S} / \mathrm{N}=3)$. The sensor was applied to detect $\mathrm{H}_{2} \mathrm{O}_{2}$ in spiked human blood serum samples with satisfactory results.
\end{abstract}

Keywords: carbon nanotubes; silver nanoparticles; nonenzymatic; sensor; hydrogen peroxide

\section{Introduction}

Carbon nanotubes (CNTs) as perfect one-dimension nanomaterials are widely applied to various fields including energy storage, heterogeneous catalysis, sensors, biosensors, and DNA theranostic, due to their excellent physicochemical performance, unique electrochemical properties, and easy functionalization [1-6]. CNTs are easily functionalized through physical ultraphonic, chemical acidification and oxidation. The functionalized multi-wall carbon nanotubes (MWCNTs) have been used as carriers to immobilize various nanoparticles and biological molecules for various applications, such as biosensors and bioassays $[7,8]$. Silver is a low-cost noble metal and silver nanostructures have remarkable catalytic activity and good electron transfer efficiency [9-11]. Silver nanostructures, including nanoparticles and nanotubes, are used to construct electrochemical sensors for the ultrasensitive detection of hydrogen peroxide [12,13], proteins [14], lactose [15], glucose [16], and hydroquinone [17]. Due to the unique properties of CNT and silver nanoparticles, the preparation of CNT/AgNPs hybrid nanocomposites has received considerable interest [18-20]. Benefitting from the synergistic effect between the AgNPs and CNT, the AgNPs/CNT hybrid nanocomposite exhibits excellent performance on electron transfer and electrocatalytic activity. Various approaches including sputter deposition [21], silver mirror reaction [22], template self-volatilization [23], one-step hydrothermal method [24], electrostatic adsorption [25,26], and in-situ chemical reduction [27], were used to prepare the AgNPs-loaded CNT (AgNPs-CNT) nanocomposites. The AgNPs-CNT nanocomposite, prepared with the electrostatic adsorption method, has less AgNPs on the CNT surface, which influences its catalytic activity. The in-situ chemical reduction of $\mathrm{Ag}^{+}$ions in dispersed 
CNT solution would increase the amount of AgNPs on the CNT surface, but the AgNPs possess irregular morphology and size due to the uncontrolled nucleation and growth processes. Moreover, CNT aggregates in aqueous solutions, which affects its performance and applications. Although, many methods and techniques are used to prepare AgNPs-CNT nanocomposites, there is still a challenge to develop a simple and mature method for the controllable growth of AgNPs on carbon nanotubes substrate.

In this article, the highly-dispersed AgNPs with a diameter of $12 \mathrm{~nm}$ were loaded on MWCNTs though a simple and facile two-step procedure. The morphology and size of the AgNPs-MWCNT nanocomposite were characterized by transmission electron microscopy (TEM), X-ray diffraction, and ICP analysis. The AgNPs-MWCNT nanocomposite was used to develop a nonenzymatic electrochemical sensor for the detection of hydrogen peroxide $\left(\mathrm{H}_{2} \mathrm{O}_{2}\right) \cdot \mathrm{H}_{2} \mathrm{O}_{2}$ is widely used as an oxidizing agent in many fields, such as the clinical, pharmaceutical, and food industries. In addition, $\mathrm{H}_{2} \mathrm{O}_{2}$ is an important marker for oxidative stress and the side product of oxidase enzyme metabolism. Hence, the determination of $\mathrm{H}_{2} \mathrm{O}_{2}$ in trace levels in biological and various water samples are of great importance. Electrocatalytic activity of AgNPs-MWCNT nanocomposite to $\mathrm{H}_{2} \mathrm{O}_{2}$ was studied by cyclic voltammetry and amperometry was used to quantify the concentration of $\mathrm{H}_{2} \mathrm{O}_{2}$. The sensor was applied to detect $\mathrm{H}_{2} \mathrm{O}_{2}$ in spiked serum samples.

\section{Results and Discussion}

\subsection{Characterization of AgNPs-MWCNT Nanocomposite}

The AgNPs-MWCNT nanocomposite was synthesized through a two-step route. First, MWCNTs were treated with strong acids to shorten the length and introduce carboxylic groups on the CNT surface. Second, the mono-dispersed AgNPs were decorated on the MWCNTs' surface by the in-situ reduction of $\mathrm{AgNO}_{3}$ with sodium citrate. The size and morphology of the as-prepared AgNPs-MWCNT nanocomposite were characterized by transmission electron microscopy (TEM). Figure 1a,b are the TEM images of the shortened MWCNTs. One can see the length of the MWCNTs is about $200 \mathrm{~nm}$ (Figure 1a) and the diameter of the MWCNTs is around $20 \mathrm{~nm}$ (Figure 1b). Figure 1c presents the typical TEM image of the AgNPs-MWCNT nanocomposites. Large amounts of AgNPs were loaded on the MWCNTs' surface and the distribution of AgNPs on the MWCNTs' surface is uniform. The diameter of AgNPs ranges from 8 to $13 \mathrm{~nm}$ (Figure 1d). The components of the AgNPs-MWCNT were determined by inductively coupled plasma atomic emission spectrometer (ICP-AES) and the Ag content in the as-prepared AgNPs-MWCNT nanocomposite is $0.2356 \mathrm{wt} \%$.

X-ray diffraction (XRD) was used to study the crystalline phases of the MWCNTs and AgNPs-MWCNT nanocomposite. As shown in Figure 2, the diffraction peaks of MWCNTs (black) at $25.8^{\circ}, 43.5^{\circ}$, and $52.5^{\circ}$ in the XRD pattern correspond to the lattice spacing of the carbon atom (002), (100), and (004), respectively [28]. The diffraction peaks of the AgNPs-MWCNT nanocomposite (red) at $38^{\circ}, 44^{\circ}, 64^{\circ}$, and $78^{\circ}$ in XRD pattern ascribes to Ag (111), (200), (220), and (311), respectively. The above XRD pattern proves that the AgNPs-MWCNT nanocomposite was successfully synthesized [29]. 


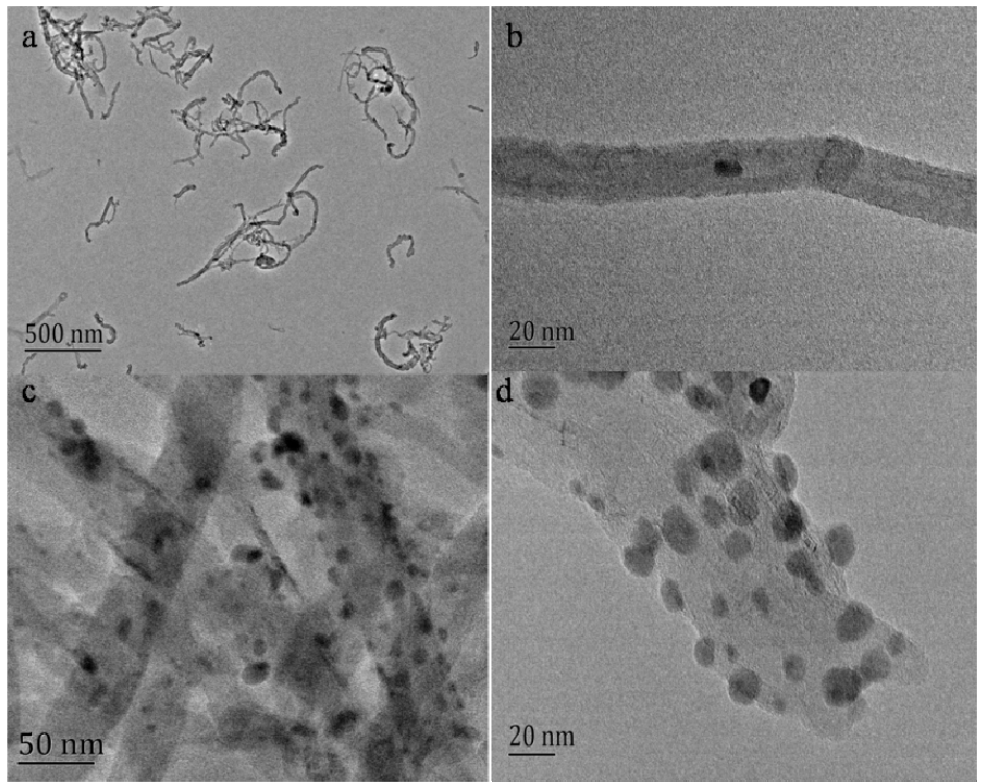

Figure 1. Typical TEM images of the shortened MWCNTs ( $\mathbf{a}$ and $\mathbf{b}$ ) and the synthesized AgNPs-MWCNT nanocomposites (c and $\mathbf{d})$.

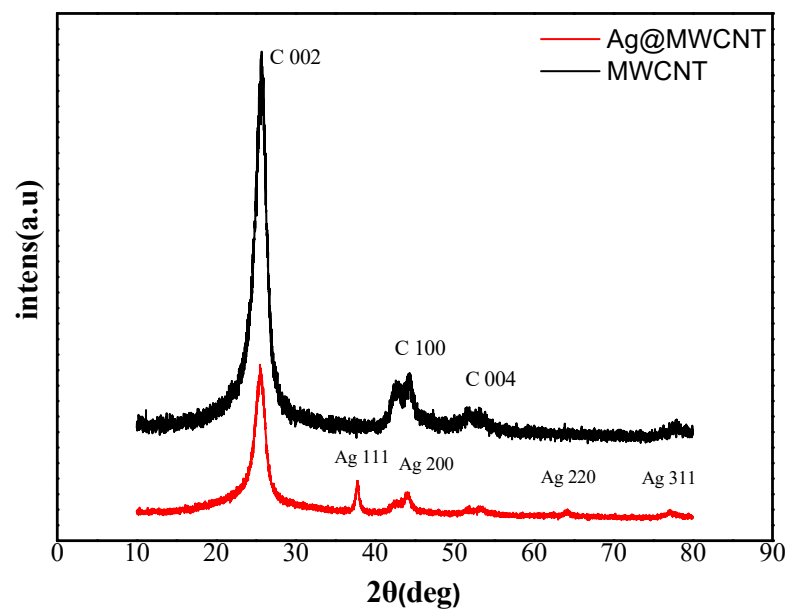

Figure 2. XRD patterns of the shortened MWCNT (black) and AgNPs-MWCNT nanocomposite (red).

\subsection{Electrocatalytic Activity of AgNPs-MWCNT Nanocomposite to $\mathrm{H}_{2} \mathrm{O}_{2}$}

The AgNPs-MWCNT nanocomposite was used to prepare a nonenzymatic electrochemical sensor for the detection of $\mathrm{H}_{2} \mathrm{O}_{2}$. The electrocatalytic activity of the AgNPs-MWCNT nanocomposite to $\mathrm{H}_{2} \mathrm{O}_{2}$ was studied by cyclic voltammetry $(\mathrm{CV})$. Figure 3a shows the typical cyclic voltammograms of the bare glassy carbon electrode (GCE), MWCNT modified GCE (MWCNT/GCE), and AgNPs-MWCNT modified GCE (AgNPs-MWCNT/GCE) in 0.1 M phosphate buffer saline (PBS, pH 7.4) containing $5 \mathrm{mM} \mathrm{H}_{2} \mathrm{O}_{2}$ at a potential scan rate of $100 \mathrm{mV} / \mathrm{s}$. As shown in Figure 3a, there is no redox peak observed on the bare GCE electrode; an obvious reduction peak (peak potential: $-0.55 \mathrm{~V}$ ) was found with AgNPs-MWCNT/GCE, and the peak current was around $-81.3 \mu \mathrm{A}$, which is much higher than that obtained with MWCNT/GCE. The above results show that the $\mathrm{H}_{2} \mathrm{O}_{2}$ were reduced at the AgNPs-MWCNT/GCE surface effectively, and the AgNPs-MWCNT has excellent electrocatalytic 
activity to the reduction of $\mathrm{H}_{2} \mathrm{O}_{2}$. The electrocatalytic mechanism of AgNPs-MWCNT to $\mathrm{H}_{2} \mathrm{O}_{2}$ reduction can be illustrated as follows [30,31]:

$$
\begin{gathered}
\mathrm{H}_{2} \mathrm{O}_{2}+2 \mathrm{e} \stackrel{\mathrm{AgNP}(\mathrm{pH} 7.4)}{\rightarrow} 2 \mathrm{OH}^{-} \\
2 \mathrm{OH}^{-} \rightarrow \mathrm{H}_{2} \mathrm{O}+\frac{1}{2} \mathrm{O}_{2}+2 \mathrm{e}
\end{gathered}
$$
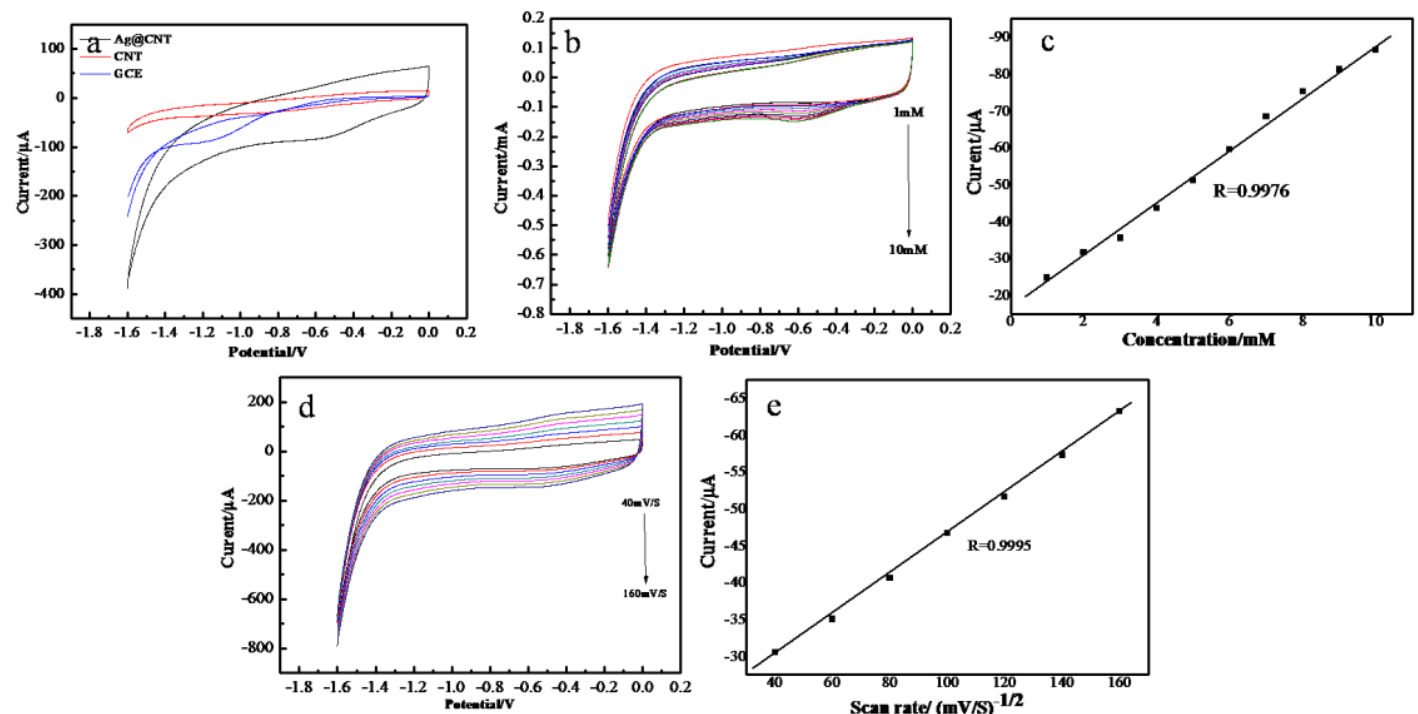

Figure 3. (a) Cyclic voltammograms of GCE, MWCNT/GCE, and AgNPs-CNT/GCE in $\mathrm{N}_{2}$-saturated $0.1 \mathrm{M}$ PBS solution containing $5 \mathrm{mM} \mathrm{H}_{2} \mathrm{O}_{2}$, potential scan rate: $100 \mathrm{mV} / \mathrm{s}$; (b) cyclic voltammograms of AgNPs-MWCNT/GCE in $\mathrm{N}_{2}$-saturated 0.1M PBS in the presence of $\mathrm{H}_{2} \mathrm{O}_{2}$ with different concentrations $(1,2,3,4,5,6,7,8,9$, and $10 \mathrm{mM})$, potential scan rate: $100 \mathrm{mV} / \mathrm{s}$; (c) relationship between the reduction peak current and $\mathrm{H}_{2} \mathrm{O}_{2}$ concentrations. (d) Cyclic voltammograms of AgNPs-MWCNT/GCE in $\mathrm{N}_{2}$-saturated $0.1 \mathrm{M}$ PBS containing $1 \mathrm{mM} \mathrm{H}_{2} \mathrm{O}_{2}$ at different scan rates $(40,60,80,100,120,140$, and $160 \mathrm{mV} / \mathrm{s}$ ); (e) relationship between the peak current vs. square root of potential scan rate.

The AgNPs on the MWCNT's surface accelerate the reduction of $\mathrm{H}_{2} \mathrm{O}_{2}$ to generate hydroxide ions $\left(\mathrm{OH}^{-}\right)$. The reduction peak potential of $\mathrm{H}_{2} \mathrm{O}_{2}$ shifts from $-0.85 \mathrm{~V}$ on MWCNT/GCE to $-0.55 \mathrm{~V}$ on AgNPs-MWCNT/GCE. The enhanced reduction current and the shifts of peak potential indicate that the AgNPs-MWCNT nanocomposite has excellent electrocatalytic activities to $\mathrm{H}_{2} \mathrm{O}_{2}$ [24]. Figure $3 \mathrm{~b}$ presents the $\mathrm{CV}$ curves of the AgNPs-MWCNT/GCE in the presence of different concentrations of $\mathrm{H}_{2} \mathrm{O}_{2}$ (0 to $10 \mathrm{mM})$. One can see the peak current at $-0.55 \mathrm{~V}$ increases with the increase of $\mathrm{H}_{2} \mathrm{O}_{2}$ concentrations. There is a linear relationship $(\mathrm{R}=0.9976)$ between the $\mathrm{H}_{2} \mathrm{O}_{2}$ concentration and the peak current (Figure 3c), indicating that the AgNPs-MWCNT/GCE can be used as a nonenzyme electrochemical sensor for the detection of $\mathrm{H}_{2} \mathrm{O}_{2}$. The effect of the potential scan rate on the peak current was studied by varying the potential scan rate from 40 to $160 \mathrm{mV} / \mathrm{s}$. Figure $3 \mathrm{~d}$ presents the cyclic voltammograms of the AgNPs-MWCNT/GCE under the different potential scan rates. The reduction peak currents increase with the increase of potential scan rates. There is a good linear relationship between the square root of potential scan rate and the peak current (Figure 3e) and the correlation coefficient is 0.9989, indicating a classic diffusion-controlled process of $\mathrm{H}_{2} \mathrm{O}_{2}$ on AgNPs-MWCNT/GCE [32].

\subsection{Amperommetric Response of $\mathrm{H}_{2} \mathrm{O}_{2}$ on $A g N P s-M W C N T / G C E$}

Amperommetry was used to inspect the possibility of the AgNPs-MWCNT/GCE as a nonenzymatic electrochemical sensor for the detection of $\mathrm{H}_{2} \mathrm{O}_{2}$. In order to obtain the optimum working potential, the amperommetric current of $1.0 \mathrm{mM} \mathrm{H}_{2} \mathrm{O}_{2}$ on AgNPs-MWCNT/GCE was measured at the working 
potential ranging from -0.1 to $-0.6 \mathrm{~V}$ with an interval of $0.1 \mathrm{~V}$ (Figure $4 \mathrm{a}$ ). It can be seen that the amperommetric response of $\mathrm{H}_{2} \mathrm{O}_{2}$ increased with the decrease of the potentials, and the highest response was obtained at $-0.5 \mathrm{~V}$. A further decrease of the working potential led to a decrease of the current. Therefore, a potential of $-0.5 \mathrm{~V}$ was selected as the optimum potential for the amperommetric detection of $\mathrm{H}_{2} \mathrm{O}_{2}$. We aimed to detect $\mathrm{H}_{2} \mathrm{O}_{2}$ in the blood or the physiological system with the AgNPs-MWCNT/GCE sensor, so we chose the $\mathrm{pH}$ value of 7.4 to match the physiological condition without further optimization. The AgNPs-MWCNT with the concentrations ranging from $1 \mathrm{mg} \mathrm{mL}^{-1}$ to $5 \mathrm{mg} \mathrm{mL}^{-1}$ were used to prepare the sensors. It was found the amperommetric responses of the AgNPs-MWCNT/GCE increased with the increase of the amount of AgNPs-MWCNT on the GCE surface, a further concentration increase resulted in signal saturation. As a result, $4 \mathrm{mg} \mathrm{mL}^{-1}$ of AgNPs-MWCNT was used to prepare the sensor. Figure $4 \mathrm{~b}$ shows the typical current-time $(\mathrm{i}-\mathrm{t})$ curve of AgNPs-MWCNT/GCE with the successive addition of $\mathrm{H}_{2} \mathrm{O}_{2}$ in $0.1 \mathrm{M} \mathrm{PBS}$ (pH 7.4) at room temperature under nitrogen atmosphere. One can see that the responsive current of AgNPs-MWCNT/GCE increases rapidly with the successive injection of $\mathrm{H}_{2} \mathrm{O}_{2}$ and reaches steady state within $3 \mathrm{~s}$. The sensitive and fast response of $\mathrm{H}_{2} \mathrm{O}_{2}$ on the AgNPs-MWCNT/GCE may be due to the large surface area of the AgNPs-MWCNT nanocomposite, which possesses a large amount of electrocatalytic active sites to improve the sensing sensitivity [33]. Figure $4 \mathrm{c}$ shows the relationship between the concentration of $\mathrm{H}_{2} \mathrm{O}_{2}$ and the step current. There are two linear ranges from 1 to $10 \mu \mathrm{M}\left(I_{r}(\mu \mathrm{A})=-0.1806 \mathrm{C}(\mu \mathrm{M})-\right.$ $\left.5.4262, R^{2}=0.9937\right)$, and from 10 to $1000 \mu \mathrm{M}\left(I_{r}(\mu \mathrm{A})=-0.0125 \mathrm{C}(\mu \mathrm{M})-7.6935, R^{2}=0.9975\right)$. According to the linear regression equation, the detection limit of $\mathrm{H}_{2} \mathrm{O}_{2}$ on AgNPs-MWCNT/GCE is estimated to be $0.38 \mu \mathrm{M}(\mathrm{S} / \mathrm{N}=3)$. Moreover, the sensitivity of the detection was about $2556 \mu \mathrm{A} \mathrm{cm}^{-2} \mathrm{mM}^{-1}$ at the low concentration range $(1$ to $10 \mu \mathrm{M})$. The above results indicate that the AgNPs-MWCNT nanocomposite possesses excellent electrocatalytic property to $\mathrm{H}_{2} \mathrm{O}_{2}$, which can be ascribed to the following reasons-first, both AgNPs and MWCNTs have excellent electron transfer efficiency, the hybrid nanocomposite (AgNPs-MWCNT) has higher electron transfer efficiency, which can enhance the reaction rate of hydrogen peroxide; second, the synthesized AgNPs possess a smaller size, well dispersion, and good uniformity deposited on MWCNT surface, which can enlarge the surface area and increase the electrocatalytic active sites of the nanocomposite; third, the synergistic effect was generated between AgNPs and CNTs, which can improve the sensitivity of the $\mathrm{H}_{2} \mathrm{O}_{2}$ detection [34]. Table 1 displays the detection limits and linear ranges of AgNPs-MWCNT/GCE and the other related sensors in literature [35-37]. The limit of detection (LOD) of the AgNPs-MWCNT sensor in this work is comparable or better than that of the other nonenzymatic $\mathrm{H}_{2} \mathrm{O}_{2}$ sensors.

Table 1. Performance comparisons of the $\mathrm{H}_{2} \mathrm{O}_{2}$ sensors fabricated with different materials.

\begin{tabular}{cccc}
\hline Modify Electrode & Linear Range $(\mu \mathbf{M})$ & LOD $(\mu \mathbf{M})$ & Ref. \\
\hline PtNPs-MWCNTs & $2-3800$ & 0.7 & {$[35]$} \\
AuNPs-MWCNT & $20-300$ & 0.4 & {$[36]$} \\
AgNCs-GO & $20-10000$ & 3.0 & {$[13]$} \\
Ag NPs-MWCNT & $50-17000$ & 0.5 & {$[37]$} \\
AgNPs-MWCNT-rGO & $100-100000$ & 0.9 & {$[24]$} \\
AgNPs-MWCNT & $1-1000$ & 0.38 & This work \\
\hline
\end{tabular}



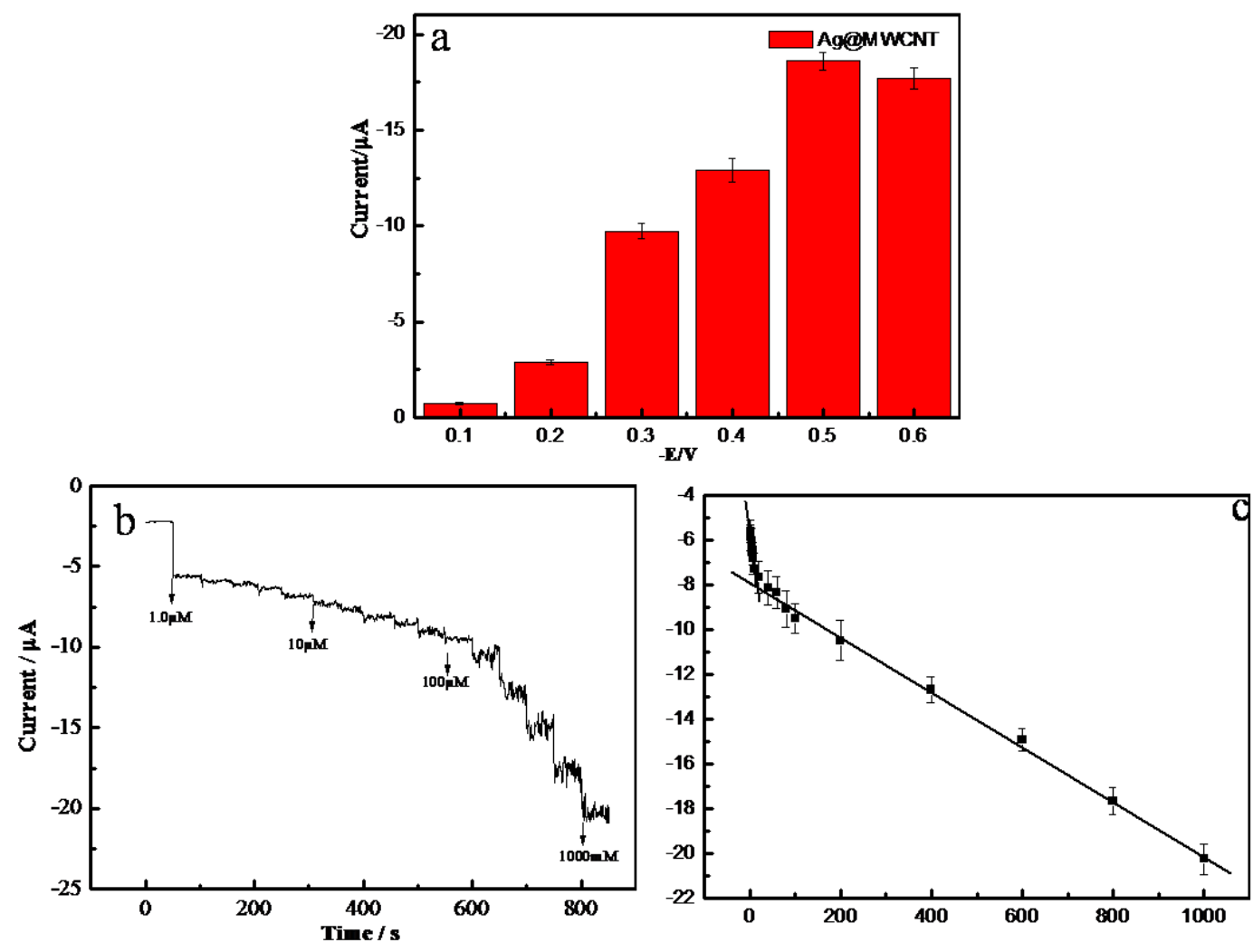

Figure 4. (a) The responsive currents of AgNPs-MWCNT/GCE in the presence of $1 \mathrm{mM} \mathrm{H}_{2} \mathrm{O}_{2}$ at different working potential from -0.1 to $-0.6 \mathrm{~V}$ with $0.1 \mathrm{~V}$ interval; (b) typical amperommetric responses of AgNPs-MWCNT/GCE to the successive addition of $\mathrm{H}_{2} \mathrm{O}_{2}$ in $0.1 \mathrm{M}$ PBS at working potential of $-0.5 \mathrm{~V}$; (c) the dependence of the responses of electrodes on $\mathrm{H}_{2} \mathrm{O}_{2}$ concentrations.

\subsection{Selectivity, Reproducibility, and Stability of the AgNPs-MWCNT/GCE Sensor}

Figure 5a shows the amperommetric responses of $0.1 \mathrm{mM}$ and $1.0 \mathrm{mM} \mathrm{H}_{2} \mathrm{O}_{2}$ in the absence and presence of $0.5 \mathrm{M}$ of potential interferences including ascorbic acid, $\mathrm{NaCl}$, fructose, sucrose, and glucose (last injection). One can see that similar responsive currents were obtained in the absence and presence of interferences. In addition, there was no responsive current observed when injecting the interferences in the absence of $\mathrm{H}_{2} \mathrm{O}_{2}$. The above results indicate that the AgNPs-MWCNT/GCE sensor has excellent selectivity toward $\mathrm{H}_{2} \mathrm{O}_{2}$ detection. The reproducibility of the AgNPs-MWCNT/GCE sensor was studied by measuring $0.1 \mathrm{mM} \mathrm{H}_{2} \mathrm{O}_{2}$ with five electrodes fabricated at the same batch (Figure 5b). Similar responsive currents were obtained and the relative standard deviation (RSD) of the five measurements was $1.2 \%$, indicating the excellent reproducibility of the sensor. The stability of AgNPs-MWCNT/GCE was tested by measuring the responsive current of $0.1 \mathrm{mM} \mathrm{H}_{2} \mathrm{O}_{2}$ for 5 days, and the sensor was kept in room temperature. As shown in Figure $5 c$, no obvious current difference was observed in five days, and the RSD of the measured currents was $1.8 \%$. The above experimental results indicate that the AgNPs-MWCNT/GCE has good stability. 


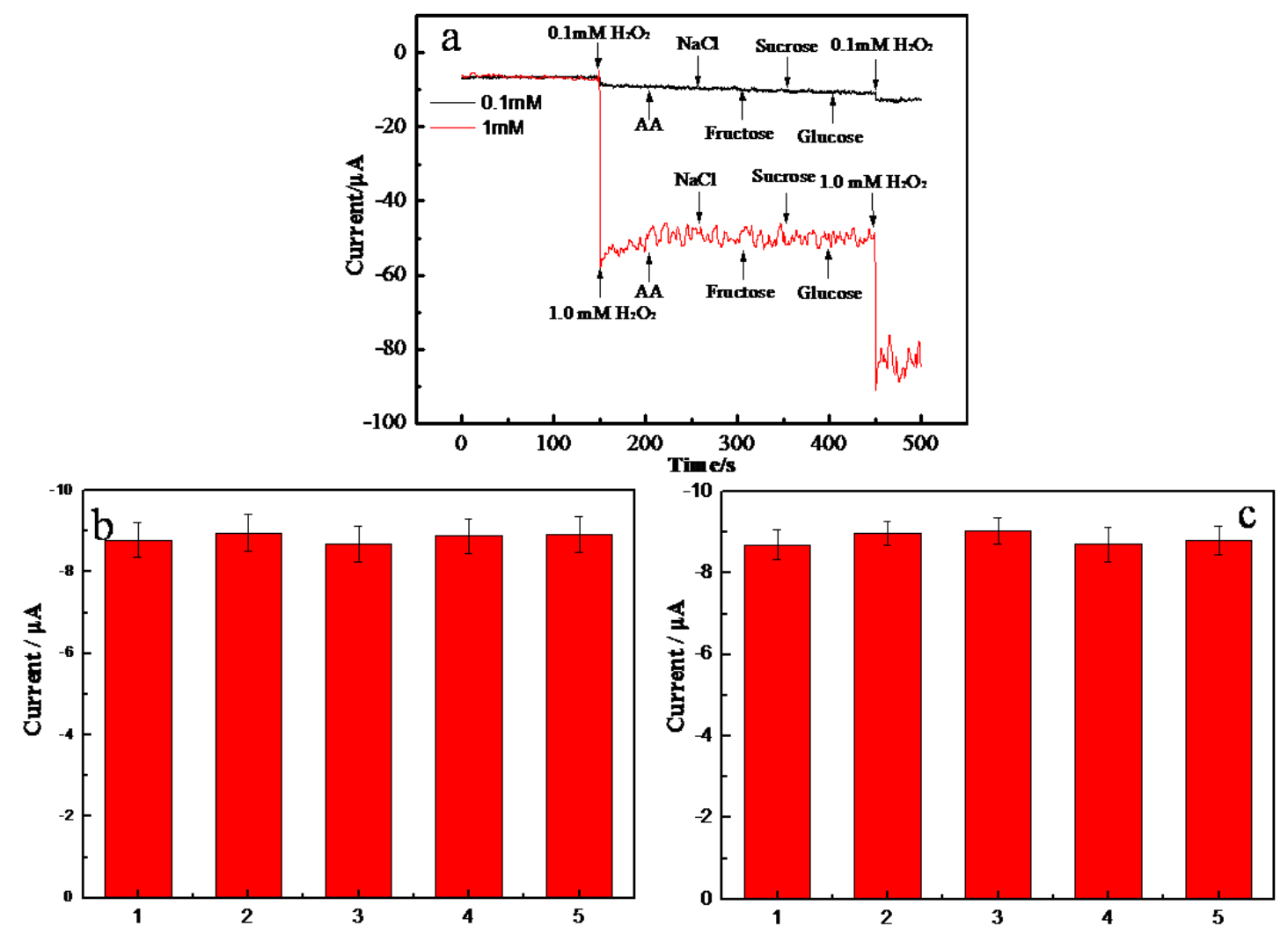

Figure 5. (a) Chronoamperometric curve (black) of the AgNPs-MWCNT/GCE in response to the successive addition of $0.1 \mathrm{mM} \mathrm{H}_{2} \mathrm{O}_{2}, 5 \mathrm{mM}$ ascorbic acid, $5 \mathrm{mM} \mathrm{NaCl}, 5 \mathrm{mM}$ fructose, $5 \mathrm{mM}$ sucrose, $5 \mathrm{mM}$ glucose and $0.1 \mathrm{mM} \mathrm{H}_{2} \mathrm{O}_{2}$ in $0.1 \mathrm{M} \mathrm{PBS}$ at a working potential of $-0.5 \mathrm{~V}$; chronoamperometric curve (red) of the AgNPs-MWCNT/GCE in response to the successive addition of $1 \mathrm{mM} \mathrm{H}_{2} \mathrm{O}_{2}, 5 \mathrm{mM}$ ascorbic acid, $5 \mathrm{mM} \mathrm{NaCl}, 5 \mathrm{mM}$ fructose, $5 \mathrm{mM}$ sucrose, $5 \mathrm{mM}$ glucose and $1 \mathrm{mM} \mathrm{H}_{2} \mathrm{O}_{2}$ in PBS at a working potential of $-0.5 \mathrm{~V}$. (b) Current responses of five equally fabricated sensors to $0.1 \mathrm{mM}$ $\mathrm{H}_{2} \mathrm{O}_{2}$. (c) Current responses of the AgNPs-MWCNT/GCE biosensor to $0.5 \mathrm{mM} \mathrm{H}_{2} \mathrm{O}_{2}$. Amperommetric measurements were performed in 5 days using the same sensor.

\subsection{Detection of $\mathrm{H}_{2} \mathrm{O}_{2}$ in Human Blood Serum}

The AgNPs-MWCNT/GCE sensor was applied to detect $\mathrm{H}_{2} \mathrm{O}_{2}$ in human blood serum (HBS). The HBS was diluted 50 times by $0.1 \mathrm{M}$ PBS (pH 7.4), and the $\mathrm{H}_{2} \mathrm{O}_{2}$ standards were added to the diluted HBS. The concentrations of $\mathrm{H}_{2} \mathrm{O}_{2}$ in the diluted HBS were fixed at 5.0, 50, and $500 \mu \mathrm{M}$, respectively. Each sample was detected three times at same condition. The data are displayed in Table 2. The recovery rates of $\mathrm{H}_{2} \mathrm{O}_{2}$ in the diluted $\mathrm{HBS}$ were $90.2,92.8$, and $96.8 \%$ respectively; and the RSD were $1.75,0.47$, and $0.61 \%$ respectively. The results indicated that the fabricated AgNPs-MWCNT/GC sensor has good ability for $\mathrm{H}_{2} \mathrm{O}_{2}$ detection in practical application.

Table 2. Results of standard addition and recovery in human blood serum.

\begin{tabular}{ccccc}
\hline Samples & Added $(\mu \mathbf{M})$ & Founded $(\mu \mathbf{M})$ & Recovery (\%) & RSD (\%) \\
\hline 1 & 5.0 & 4.5 & 90.2 & 1.75 \\
2 & 100 & 92.8 & 92.8 & 0.47 \\
3 & 500 & 483.8 & 96.8 & 0.61 \\
\hline
\end{tabular}




\section{Materials and Methods}

\subsection{Materials and Instruments}

MWCNT was purchased from Nanjing XFNano Materials Technology Co., Ltd. (Nanjing, China). Silver nitrate $\left(\mathrm{AgNO}_{3}, 99.5 \%\right)$, sodium citrate, glucose, ascorbic acid, fructose, phosphate buffer saline (PBS, PH 7.4, $0.1 \mathrm{M}$ ), and lactose were purchased from Sigma (Shanghai, China). Sulfuric acid $\left(\mathrm{H}_{2} \mathrm{SO}_{4}\right.$, $98 \%)$, nitric acid $\left(\mathrm{HNO}_{3}, 98 \%\right)$, and hydrogen peroxide $\left(\mathrm{H}_{2} \mathrm{O}_{2}\right)$ were purchased from Sinopharm Chemical Reagent Co., Ltd. (Beijing, China). Human blood plasma was purchased from Senbeijia Biotechnology Co., Ltd. (Nanjing, China). All the reagents were of analytical grade and used as received without further purification. Ultrapure water (resistance $>18 \mathrm{M} \Omega \mathrm{cm}^{-1}$, Milli-Q purification system) was used in all of the experiments.

Electrochemical studies were performed on a CHI 660D electrochemical system (Chenhua, Shanghai, China). The three-electrode system consists of a AgNPs-MWCNT modified glassy carbon working electrode, a $\mathrm{Ag} / \mathrm{AgCl} / \mathrm{KCl}$ (saturated) reference electrode, and a platinum wire counter electrode. The morphology and size of the CNT and AgNPs-MWCNT were characterized by TEM (JEOL, Kyoto, Japan, 2100F, 200KV). XRD measurements were performed on a Shimadzu XRD-6000 (Shimadzu, Kyoto, Japan) using Cu K $\alpha$ radiation (1.5406 ̊) and operated at $36 \mathrm{kV}$ and $20 \mathrm{~mA}$. All the experiments were carried out at room temperature. The content of Ag in the AgNPs-MWCNT nanocomposite was determined by ICP-AES (TJA IRIS Advantage ER/S, Thermo, Franklin, MA, USA).

\subsection{Synthesis of AgNPs-MWCNT Nanocomposite}

The MWCNTs were shortened and functionalized with the previous reported method [38]. Briefly, $40 \mathrm{mg}$ of MWCNTs, $19.2 \mathrm{~mL}$ of concentrated sulfuric acid, and $6.4 \mathrm{~mL}$ of concentrated nitric acid were added to a glass flask with a volume of $50 \mathrm{~mL}$. The mixture was sonicated for $6 \mathrm{~h}$ at room temperature and separated through centrifugation at 8,000 rpm for 10min; then the MWCNT pellet was washed several times with deionized water and ethanol, respectively. The final product was dried for $24 \mathrm{~h}$ at $35^{\circ} \mathrm{C}$ under nitrogen atmosphere.

The AgNPs-MWCNT nanocomposite was prepared by a reported method with a slight modification [39]. Three milligrams of the functionalized MWCNTs and $600 \mu \mathrm{L}$ of $0.1 \mathrm{~g} \mathrm{~mL}^{-1}$ sodium citrate solution were dispersed in $30 \mathrm{~mL}$ of deionized water, the mixture was heated at $100{ }^{\circ} \mathrm{C}$ for $5 \mathrm{~h}$ under vigorous stirring. Then, the mixture was cooled to $60^{\circ} \mathrm{C}$, and the $96.6 \mu \mathrm{L}$ of $0.01 \mathrm{M}$ silver nitrate solution was added to the mixture. The mixture solution continued to react for $5 \mathrm{~h}$ at $60{ }^{\circ} \mathrm{C}$ under vigorous stirring. After the system was cooled to room temperature, the resulting product (AgNPs-MWCNT) was separated though centrifugation, washed three times with deionized water and ethanol, and dried for $48 \mathrm{~h}$ at $35^{\circ} \mathrm{C}$ under nitrogen atmosphere.

\subsection{Preparation of the AgNPs-MWCNT/GCE}

The GCE $(\Phi=3 \mathrm{~mm}$ ) was polished with 0.5 and $0.05 \mu \mathrm{m}$ alumina slurries, respectively, and followed by sonication in deionized water and ethanol. The electrode was dried under nitrogen atmosphere. A $10 \mu \mathrm{L}$ of AgNPs-MWCNT aqueous solution $\left(4 \mathrm{mg} \mathrm{mL}^{-1}\right)$ was dropped on the cleaned GCE surface and dried in air, then a $10 \mu \mathrm{L}$ of Nafion $(0.05 \mathrm{wt} \%)$ was dropped again and dried at room temperature. The MWCNT-modified GCE was prepared in the same way.

\subsection{Electrochemical Measurements}

A three-electrode cell contains AgNPs-MWCNT/GCE as working electrode, platinum wire as the counter electrode, and $\mathrm{Ag} / \mathrm{AgCl}$ as the reference electrode. Cyclic voltammograms $(\mathrm{CV})$ were obtained at the potential range between 0.2 and $-1.6 \mathrm{~V}$ in $0.1 \mathrm{M}$ PBS at $\mathrm{pH} 7.4$ at a scan rate of $100 \mathrm{mV} \mathrm{s}^{-1}$. Amperommetric experiments were carried out in $20.0 \mathrm{~mL}$ of $0.1 \mathrm{M}$ PBS (pH 7.4) with the successive addition of $\mathrm{H}_{2} \mathrm{O}_{2}$ under mild stirring. The electrode potential was set at $-0.5 \mathrm{~V}$ (vs. Ag/AgCl). Before the experiment, all the PBS solution was purged with high-purity nitrogen for at least $30 \mathrm{~min}$. 


\section{Conclusions}

The AgNPs-MWCNT nanocomposite were successfully prepared through a simple and facile two-step method. The advantage of this method was that the silver nanoparticles were highly dispersed on the functionalized carbon nanotubes. The AgNPs-MWCNT nanocomposite was used to prepare a nonenzymatic electrochemical sensor for the detection of $\mathrm{H}_{2} \mathrm{O}_{2}$ with wide linear range, low detection limit, and excellent reproducibility and stability. The sensor was applied to detect $\mathrm{H}_{2} \mathrm{O}_{2}$ in spiked human blood serum with satisfactory results.

Author Contributions: D.X., and B.H. did the experiments, analyzed the data, and wrote the paper. L.Q. and G.L. and X.Z. conceived, designed the experiment, and elaborated the paper, and all authors approved the final paper.

Funding: This research was supported by the National Natural Science Foundation of China (Grant No. 31700735), the National Natural Science Foundation of Anhui Province (Grant No. 1908085MB54, 1808085QH264), and the Student's Platform for Innovation and Entrepreneurship Training Program of Anhui Province (Grant No. S201910879210). G. Liu acknowledges the support from the Wanjiang scholars in Anhui Province, China.

Conflicts of Interest: The author(s) declare that they have no competing interests. The funders had no role in the design of the study; in the collection, analyses, or interpretation of data; in the writing of the manuscript, or in the decision to publish the results.

\section{References}

1. Varghese, S.H.; Nair, R.; Nair, B.G.; Hanajiri, T.; Maekawa, T.; Yoshida, Y.; Kumar, S. Sensors based on carbon nanotubes and their applications: A review. Curr. Nanosci. 2010, 6, 331-346. [CrossRef]

2. Park, S.; Vosguerichian, M.; Bao, Z. A review of fabrication and applications of carbon nanotube film-based flexible electronics. Nanoscale 2013, 5, 1727-1752. [CrossRef] [PubMed]

3. Gooding, J.J. Nanostructuring electrodes with carbon nanotubes: A review on electrochemistry and applications for sensing. Electrochim. Acta 2005, 50, 3049-3060. [CrossRef]

4. Zhang, Q.; Zhao, B.; Yan, J.; Song, S.; Min, R.; Fan, C. Nanotube-based colorimetric probe for ultrasensitive detection of ataxia telangiectasia mutated protein. Anal. Chem. 2011, 83, 9191-9196. [CrossRef] [PubMed]

5. Qiu, W.; Xu, H.; Takalkar, S.; Gurung, A.S.; Liu, B.; Zheng, Y.; Guo, Z.; Baloda, M.; Baryeh, K.; Liu, G. Carbon nanotube-based lateral flow biosensor for sensitive and rapid detection of DNA sequence. Biosens. Bioelectron. 2015, 64, 367-372. [CrossRef] [PubMed]

6. Luksirikul, P.; Tedsree, K.; Moloney, M.G.; Green, M.L.H.; Tsang, S.C.E. Electron promotion by surface functional groups of single wall carbon nanotubes to overlying metal particles in a fuel-cell catalyst. Angew. Chem. 2012, 51, 6998-7001. [CrossRef] [PubMed]

7. Peng, Z.; Shao, C.; Zhang, Z.; Zhang, M.; Mu, J.; Guo, Z.; Liu, Y.C. In situ assembly of well-dispersed Ag nanoparticles (AgNPs) on electrospun carbon nanofibers (CNFs) for catalytic reduction of 4-nitrophenol. Nanoscale 2011, 3, 3357-3363.

8. Guo, D.J.; Li, H.L. High dispersion and electrocatalytic properties of palladium nanoparticles on single-walled carbon nanotubes. J. Colloid Interf. Sci. 2005, 286, 274-279. [CrossRef]

9. Rycenga, M.; Cobley, C.M.; Zeng, J.; Li, W.; Moran, C.H.; Zhang, Q.; Qin, D.; Xia, Y. Controlling the synthesis and assembly of silver nanostructures for plasmonic applications. Chem. Rev. 2011, 111, 3669-3712. [CrossRef]

10. Gilroy, K.D.; Yang, X.; Xie, S.; Zhao, M.; Qin, D.; Xia, Y. Shape-controlled synthesis of colloidal metal nanocrystals by replicating the surface atomic structure on the seed. Adv. Mater. 2018, 30, 1706312-1706337. [CrossRef] [PubMed]

11. Rashid, M.H.; Mandal, T.K. Synthesis and catalytic application of nanostructured silver dendrites. J. Phys. Chem. C 2007, 111, 16750-16760. [CrossRef]

12. Wang, Y.; Yang, X.J.; Bai, J.; Jiang, X.; Fan, G. High sensitivity hydrogen peroxide and hydrazine sensor based on silver nanocubes with rich $\{100\}$ facets as an enhanced electrochemical sensing platform. Biosens. Bioelectron. 2013, 43, 180-185. [CrossRef] [PubMed]

13. Zhong, L.J.; Gan, S.Y.; Fu, X.G.; Li, F.; Han, D.; Guo, L.; Niu, L. Electrochemically controlled growth of silver nanocrystals on graphene thin film and applications for efficient nonenzymatic $\mathrm{H}_{2} \mathrm{O}_{2}$ biosensor. Electrochim. Acta 2013, 89, 222-228. [CrossRef] 
14. Qu, F.L.; Lu, H.M.; Yang, M.H.; Deng, C. Electrochemical immunosensor based on electron transfer mediated by graphene oxide initiated silver enhancement. Biosens. Bioelectron. 2011, 26, 4810-4814. [CrossRef] [PubMed]

15. Bollella, P.; Schulz, C.; Favero, G.; Mazzei, F.; Ludwig, R.; Gorton, L.; Antiochia, R. Green synthesis and characterization of gold and silver nanoparticles and their application for development of a third generation lactose biosensor. Electroanalysis 2016, 29,77-86. [CrossRef]

16. Lu, W.B.; Luo, Y.L.; Chang, G.H.; Sun, X. Synthesis of functional $\mathrm{SiO}_{2}$-coated graphene oxide nanosheets decorated with $\mathrm{Ag}$ nanoparticles for $\mathrm{H}_{2} \mathrm{O}_{2}$ and glucose detection. Biosens. Bioelectron. 2011, 26, 4791-4797. [CrossRef] [PubMed]

17. Goulart, L.A.; Gonçalves, R.; Correa, A.A.; Pereira, E.C.; Mascaro, L.H. Synergic effect of silver nanoparticles and carbon nanotubes on the simultaneous voltammetric determination of hydroquinone, catechol, bisphenol A and phenol. Microchim. Acta 2018, 185, 12-20. [CrossRef]

18. Castle, A.B.; Gracia-Espino, E.; Nieto-Delgado, C.; Terrones, H.; Terrones, M.; Hussain, S. Hydroxyl-functionalized and $\mathrm{N}$-doped multiwalled carbon nanotubes decorated with silver nanoparticles preserve cellular function. ACS Nano 2011, 5, 2458-2466. [CrossRef]

19. Barbinta-Patrascu, M.E.; Ungureanu, C.; Iordache, M.S.; Iordache, A.M.; Bunghez, I.; Ghiurea, M.; Badea, N.; Fierascu, R.; Stamatin, I. Eco-designed biohybrids based on liposomes, mint-nanosilver and carbon nanotubes for antioxidant and antimicrobial coating. Mater. Sci. Eng. C 2014, 39, 177-185. [CrossRef]

20. Azadbakht, A.; Abbasi, A.R.; Derikvand, Z.; Karimi, Z.; Roushani, M. Surface-Renewable AgNPs/CNT/rGO Nanocomposites as Bifunctional Impedimetric Sensors. Nano-MicroLett. 2017, 9, 1-11. [CrossRef]

21. Tammeveski, L.; Erikson, H.; Sarapuu, A.; Kozlova, J.; Ritslaid, P.; Sammelselg, V.; Tammeveski, K. Electrocatalytic oxygen reduction on silver nanoparticle/multi-walled carbon nanotube modified glassy carbon electrodes in alkaline solution. Electrochem. Commun. 2012, 20, 15-18. [CrossRef]

22. Larrude, D.G.; Maia da Costa, M.E.H.; Freire, F.L. Synthesis and Characterization of Silver Nanoparticle-Multiwalled Carbon Nanotube Composites. J. Nanomater. 2014, 654068, 1-7. [CrossRef]

23. Jiang, H.; Zhang, H.X.; Fu, Y.; Guo, S.; Hu, Y.; Zhang, L.; Liu, Y.; Liu, H.; Li, C. Self-Volatilization approach to mesoporous carbon nanotube/silver nanoparticle hybrids: The role of silver in boosting Li ion storage. ACS Nano 2016, 10, 1648-1654. [CrossRef] [PubMed]

24. Lorestani, F.; Shahnavaz, Z.; Mn, P.; Alias, Y.; Manan, N.S.A. One-step hydrothermal green synthesis of silver nanoparticle-carbon nanotube reduced-graphene oxide composite and its application as hydrogen peroxide sensor. Sens. Actuators B 2015, 208, 389-398. [CrossRef]

25. Yua, A.; Wang, Q.X.; Yong, J.W.; Mahon, P.J.; Malherbe, F.; Wang, F.; Zhang, H.; Wang, J. Silver nanoparticle-carbon nanotube hybrid films: Preparation and electrochemical sensing. Electrochim. Acta 2012, 74, 111-116. [CrossRef]

26. Shi, Y.; Liu, Z.L.; Zhao, B.; Sun, Y.; Xu, F.; Zhang, Y.; Wen, Z.; Yang, H.; Li, Z. Carbon nanotube decorated with silver nanoparticles via noncovalent interaction for a novel nonenzymatic sensor towards hydrogen peroxide reduction. J. Electroanal. Chem. 2011, 656, 29-33. [CrossRef]

27. Zhao, W.; Wang, H.C.; Qin, X.; Wang, X.; Zhao, Z.; Miao, Z.; Chen, L.; Shan, M.; Fang, Y.; Chen, Q. A novel nonenzymatic hydrogen peroxide sensor based on multi-wall carbon nanotube/silver nanoparticle nanohybrids modified gold electrode. Talanta 2009, 80, 1029-1033. [CrossRef] [PubMed]

28. Endo, M.; Takeuchi, K.; Hiraoka, T.; Furuta, T.; Kasai, T.; Sun, X.; Kiang, C.H.; Dresselhaus, M.S. Stacking nature of graphene layers in carbon nanotubes and nanofibers. J. Phys. Chem. Solids. 1997, 58, 1707-1712. [CrossRef]

29. Wiley, B.J.; Chen, Y.; McLellan, J.M.; Xiong, Y.; Li, Z.Y.; Ginger, D.; Xia, Y. Synthesis and optical properties of silver nanobars and nanorice. Nano Lett. 2007, 7, 1032-1036. [CrossRef]

30. Maduraiveeran, G.; Kundu, M.; Sasidharan, M. Electrochemical detection of hydrogen peroxide based on silver nanoparticles via amplified electron transfer process. J Mater. Sci. 2018, 53, 8328-8338. [CrossRef]

31. Qi, Y.; Bai, J.; Ding, X.; Zhang, H.M. Electrochemically Prepared Three-dimensional Porous Nitrogen-doped Graphene Modified Electrode for Non-enzymatic Detection of Hydrogen Peroxide. Electroanalysis 2017, 29, 1-8. [CrossRef]

32. Ma, B.; Konga, C.; Hu, X.X.; Liu, K.; Huang, Q.; Lv, J.; Lu, W.; Zhang, X.; Yang, Z.; Yang, S. A sensitive electrochemical nonenzymatic biosensor for the detection of $\mathrm{H}_{2} \mathrm{O}_{2}$ released from living cells based on ultrathin concave Ag nanosheets. Biosens. Bioelectron. 2018, 106, 29-36. [CrossRef] [PubMed] 
33. Yang, H.X.; Hou, J.G.; Wang, Z.H.; Zhang, T.; Xu, C. An ultrasensitive biosensor for superoxide anion based on hollow porous PtAg nanospheres. Biosens. Bioelectron. 2018, 117, 429-435. [CrossRef] [PubMed]

34. Dai, H.; Chen, Y.; Niu, X.Y.; Pan, C.; Chen, H.; Chen, X. High-performance electrochemical biosensor for nonenzymatic $\mathrm{H}_{2} \mathrm{O}_{2}$ sensing based on $\mathrm{Au} @ \mathrm{CCo}_{3} \mathrm{O}_{4}$ heterostructures. Biosens. Bioelectron. 2018, 118, $36-43$. [CrossRef] [PubMed]

35. Fang, Y.; Zhang, D.; Qin, X.; Miao, Z.; Takahashi, S.; Anzai, J.; Chen, Q. A non-enzymatic hydrogen peroxide sensor based on poly (vinyl alcohol)-multiwalled carbon nanotubes-platinum nanoparticles hybrids modified glassy carbon electrode. Electrochim. Acta 2012, 70, 266-271. [CrossRef]

36. Rajabzade, H.; Daneshgar, P.; Tazikeh, E.; Mehrabian, R.Z. Functionalized carbon nanotubes with gold nanoparticles to fabricate a sensor for hydrogen peroxide determination. Eur. J. Chem. 2012, 9, 2540-2549. [CrossRef]

37. Lu, W.; Chang, G.; Luo, Y.; Liao, F.; Sun, X. Method for effective immobilization of Ag nanoparticles/graphene oxide composites on single-stranded DNA modified gold electrode for enzymeless $\mathrm{H}_{2} \mathrm{O}_{2}$ detection. J. Mater. Sci. 2011, 46, 5260-5266. [CrossRef]

38. Wepasnick, K.A.; Smith, B.A.; Schrote, K.E.; Wilson, H.K.; Diegelmann, S.R.; Fairbrother, D.H. Surface and structural characterization of multi-walled carbon nanotubes following different oxidative treatments. Carbon 2011, 49, 24-36. [CrossRef]

39. Gao, R.; Hu, N.; Yang, Z.; Zhu, Q.; Chai, J.; Su, Y.; Zhang, L.; Zhang, Y. Paper-like graphene-Ag composite films with enhanced mechanical and electrical properties. Nanoscale Res. Lett. 2013, 8, 1-8. [CrossRef] [PubMed]

Sample Availability: The AgNPs-MWCNT nanocomposite are available from the authors.

(C) 2019 by the authors. Licensee MDPI, Basel, Switzerland. This article is an open access article distributed under the terms and conditions of the Creative Commons Attribution (CC BY) license (http://creativecommons.org/licenses/by/4.0/). 